\title{
High Blood Pressure and Diet Quality in the Spanish Childhood Population
}

\author{
M. Dolores Marrodán ${ }^{1,3 *}$, Noemí López-Ejeda ${ }^{1,3}$, Marisa González-Montero De Espinosa', Jesús R. Martínez-Álvarez ${ }^{1,3}$, Margarita \\ Carmenate $^{2}$, M. Dolores Cabañas ${ }^{2}$, Dolores Cabañas $\mathbf{M}^{1}$, Antonio Villarino ${ }^{1,3}$, Verónica Calabria ${ }^{2}$, José L. Pacheco ${ }^{1}$ and Juan F. Romero- \\ Collazos $^{1,4}$
}

${ }^{1}$ Research Group EPINUT-UCM, Faculties of Medicine and Biology at Complutense University of Madrid, Spain

${ }^{2}$ Faculty of Science, Department of Biology, Autónoma University of Madrid, Spain

${ }^{3}$ Spanish Society of Dietetic and Food Science (SEDCA), Spain

${ }^{4}$ Depor Clinic, Sport Medicine and Physiotherapy, Madrid, Spain

\begin{abstract}
The objective is to analyze the association between the degree of compliance with Mediterranean Diet and blood pressure in 1078 Spanish schoolchildren (514 boys, 564 girls) aged 9 to 16 years. We measured weight (kg), height $(\mathrm{cm})$, waist circumference $(\mathrm{cm})$, skinfold thicknesses (bicipital, tricipital, subscapular and suprailiac) and blood pressure. The Waist-to-Height Ratio (WtHR), Body Mass Index (BMI), and the percent body fat (\%BF) were calculated. Subjects were classified as "underweight", "normal weight", "overweight" or "obese" according to the International Obesity Task Force (IOTF). Diet quality was assessed by the KIDMED Index and the hypertensive status according to National High Blood Pressure Education Program Working Group.
\end{abstract}

Results show that media values of systolic and diastolic blood pressure significantly increase at the same time that diminished the quality of the diet. Schoolchildren with high blood pressure (4.66\% boys; $4.78 \%$ girls) are not distributed uniformly in the different KIDMED categories. In the "poor" diet category (KIDMED-score <3) there were $8.33 \%$ of hypertensive children, in the "average" category (KIDMED-score 3-7) there were a $3.38 \%$ and, by contrast, there were not hypertensive children in "good" category (KIDMED-score > 7). A multiple linear regression analysis found that KIDMED index had a negative correlation with systolic and diastolic pressure. Also BMI and WtHR were positively correlated with both blood pressure levels, and \% BF was associated only with diastolic BP. In conclusion, although the KIDMED index is a fast and simple tool to assess diet quality, it clearly reveals an inverse association between adherence to Mediterranean diet and blood pressure in healthy Spanish schoolchildren.

Keywords: Blood pressure; Mediterranean diet; Schoolchildren; Body mass index; Body fat; Waist to height ratio

Abbreviations: MD: Mediterranean Diet; BP: Blood Pressure; SBP: Systolic Blood Pressure; DBP: Diastolic Blood Pressure; HBP: High Blood Pressure; \%BF: Percent Body Fat; BMI: Body Mass Index; WtHR: Waist to Height Ratio

\section{Introduction}

Review studies have reported that, on average, hypertension affects $33.2 \%$ of people in developing countries and also to $40.8 \%$ in developed ones, although there is a significant worldwide variation $[1,2]$. However, this problem does not only affect the adult population. The metanalysis of Kavey et al. reported that between $1 \%$ and $5 \%$ of children and adolescents in the world, were hypertensive [3].

Recent studies conducted in geographic and ethnically diverse countries like the United States, Canada, Venezuela, Mexico, India and China have shown that these values have risen in recent years in parallel with the progressive increase in childhood obesity [4-7]. In the study on high school students, conducted by McNiece et al., the prevalence of High Blood Pressure (HBP) was over $30 \%$ in obese boys and from $23 \%$ to $30 \%$ in obese girls, depending on ethnicity [8]. In this sense, the authors found a close association between Blood Pressure (BP) and weight excess in Spanish schoolchildren, confirming that between 6 and 16 years, the risk of hypertension increases significantly with Body Mass Index (BMI), fat percentage, and abdominal adiposity measured by the Waist to Height Ratio (WtHR).

During childhood, HBP is associated with certain health problems, such as left ventricular hypertrophy, thickening of the carotid vessel wall, retinal vascular changes, and even subtle cognitive changes [9].
There is also evidence that BP levels in infancy predict BP later in life, so that prevention of childhood hypertension is the first step to reduce cardiovascular disease in adults. Preventive measures are aimed at reducing excess weight, through physical activity and improving diet, increasing consumption of vegetable foods rich in potassium, calcium and magnesium, and lowering the intake of meat and rich products in fat and sodium. This kind of diet known as DASH (Dietary Approaches to Stop Hypertension) has also been recommended by the Committee on Atherosclerosis, Hypertension, and Obesity in the Young (AHOY) dependent on the American Heart Association and its effectiveness has been proven at the clinical level [10-12].

The traditional diet in Mediterranean countries broadly in the past was characterized by an abundance of vegetal origin foods, such as bread, pasta, vegetables, salads, legumes, fruits and olive oil as the main source of fat, likewise a low intake of red meat and moderate consumption of fish, poultry, dairy and eggs. The nutritional transition and diet globalization are modifying this pattern in the southern European countries. Also, the rising prices of food items as

*Corresponding author: M.Dolores Marrodán, Faculty of Biology,Departmental Unit of Physical Anthropology, Complutense University of Madrid, José Antonio Novais 2, 28040 Madrid, Spain, E-mail: marrodan@bio.ucm.es

Received April 30, 2013; Accepted May 27, 2013; Published May 29, 2013

Citation: Marrodán MD, López-Ejeda N, González-Montero de Espinosa M, Martínez-Álvarez JR, et al. (2013) High Blood Pressure and Diet Quality in the Spanish Childhood Population. J Hypertens 2: 115. doi:10.4172/21671095.1000115

Copyright: (C) 2013 Marrodán MD, et al. This is an open-access article distributed under the terms of the Creative Commons Attribution License, which permits unrestricted use, distribution, and reproduction in any medium, provided the original author and source are credited. 
a result of current economic crisis, is facilitating the abandonment of traditional habits [13]. Particularly in Spain, the level of adherence to the Mediterranean Diet (MD) is estimated at $50 \%$, with a significant reduction in the last two decades [14-17].

The interest in promote again this type of feeding, is based on two fundamental factors. First, the extensive scientific evidence derived from epidemiological studies that demonstrate benefits of MD for cardiovascular health [18]. Secondly the good palatability and acceptance of this diet that can be used in non-pharmacological management of patients at risk of diseases related to the metabolic syndrome [19].

The effect on the reduction of $\mathrm{BP}$ is well documented in adults since the last three decades [20]. The PREDIMED Study (PREvención con DIetaMEDiterránea) showed, in Spanish population, that the MD has a greater effect on the reduction of cardiovascular morbidity and BP levels than a conventional low-fat diet [21]. In children and adolescents, this topic is still poorly explored and that is why the aim of the present paper is to analyze the association between the degree of compliance to MD and BP in Spanish school children (22).

\section{Material and Methods}

We conducted a cross-sectional study involving a sample of 1078 schoolchildren ( 514 boys, 564 girls) between 9 and 16 years, sons and grandsons of Spanish parents. The data was collected from 2004 to 2008 in 15 Primary and High Schools of Community of Madrid (Spain). The socioeconomic characteristics of the students were ranked in the intermediate level in terms of parental occupation and educational level $(29,20 \%$ were college graduates, $31,44 \%$ were high school or vocational school graduates, and $39,36 \%$ had a primary education). The primary and secondary schools included were those that showed an interest in participating in the project, with the support of the Education Department of the Community of Madrid. We required the informed consent of the parents or guardians, in accordance with the Helsinki Declaration and Spanish Organic Law, for the Protection of Personal Data (15/1999, of December 13) [23]. The exclusion criterion was the presence of any chronic disease, including diagnosed HBP.

We measured the weight $(\mathrm{kg})$, height $(\mathrm{cm})$, waist circumference $(\mathrm{cm})$ and skinfold thicknesses (bicipital, tricipital, subscapular and suprailiac) ( $\mathrm{mm})$, employing homologated anthropometric instruments and following the protocols of the International Biological Programme and the International Society for the Advancement of Kinanthropometry $[24,25]$. The WtHR was calculated by dividing the waist circumference by the height and the BMI by dividing the weight $(\mathrm{kg})$ by the height squared $(\mathrm{m})$. The sum of the four skinfold thicknesses was computed and the percent body fat $(\% \mathrm{BF})$ was determined using the Siri equation once the density had been estimated by applying the equation proposed by Brook or Durnin and Rahaman, depending on age. Subjects were classified as "underweight", "normal weight", "overweight" or "obese" according to the International Obesity Task Force (IOTF) standards published by Cole et al. [26-30].

BP was measured after a 10 minutes rest, using a mercury sphygmomanometer and Riester stethoscope. With the child in a sitting position, with back support, feet flat on the floor and right arm extended, Systolic Blood Pressure (SBP) and Diastolic Blood Pressure (DBP) were measured using, as reference, Korotkoff phases $\mathrm{I}$ and $\mathrm{V}$, respectively. The measurements were performed 3 times, since normally, the pressure tends to stabilize when the child becomes accustomed to the method and reduces anxiety. The lowest of the 3 values was considered valid. As classification criteria, we used the tables from the RICARDIN study (RIesgoCARDiovascular en la INfancia [Cardiovascular Risk in Children]) [31]. In accordance with the recommendations of the National High Blood Pressure Education Program Working Group and the Cook et al. proposal to define metabolic syndrome in childhood, we considered normotensive those boys and girls with BP levels below the 90th percentile of the standard $[32,33]$. Children with SBP and/or DBP equal or higher than this cutoff point were grouped in the HBP category.

To assess the diet quality of the schoolchildren, it was used the KIDMED Index (Mediterranean Diet Quality Index in children and adolescents) that was developed for Spanish population by Serra Majem et al. [34]. The KIDMED Index is a food consumption frequency test, based on the MD which is considered the ideal healthy diet for this population.

This questionnaire consists of 16 affirmative items about which the child must answer by saying if the statement is true or false. Each item has a positive or negative associated punctuation. At the end of the test the overall score reflects the diet quality, so the children who is below 3 points have a very low quality diet ("poor" category), if the punctuation is between 4 and 7 the diet needs improvement ("average" category) and if child have 8 or more points is considered that have a healthy diet ("good" category).

The mean and standard deviation were calculated for continuous variables and percentage for categorical parameters. Tested normality of distributions (Kolmogorof-Smirnov test) parametrical (t-test, ANOVA) or no parametrical test (Mann Whitney U) was used to assess differences between groups. For percentages, differences were assessed by Chi-Squared test. Multivariable correlations among analyzed variables were performed applying multiple linear regression models. Software SPSS version 19.0 (SPSS Inc. Chicago, IL, USA) was used for the statistical procedures.

\section{Results}

Excluding WtHR, all measurements shown significant changes with age $(\mathrm{p}<0.001)$. Boys had higher height, weight, and waist circumference than girls, from age $12(\mathrm{p}<0.05)$, while girls had a higher values for sum of skinfolds and $\% \mathrm{BF}$ from 11 years $(\mathrm{p}<0.001)$ (Table 1$)$. There were no differences in BMI between girls and boys, and distribution by nutritional categories was similar in both sexes. As shown in figure 1, excess of weight (overweight plus obesity) was of $31.3 \%$ in males and $29.6 \%$ in females. According the expected pattern, SBP and DBP, also

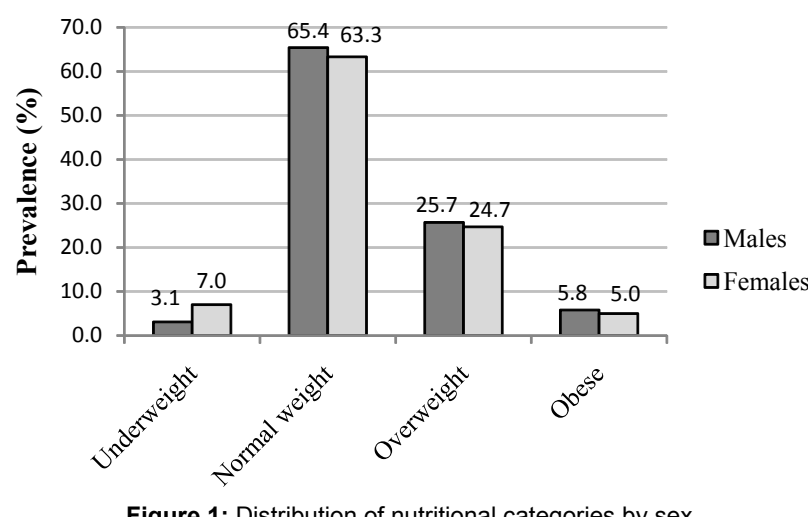

Figure 1: Distribution of nutritional categories by sex. 
Citation: Marrodán MD, López-Ejeda N, González-Montero de Espinosa M, Martínez-Álvarez JR, et al. (2013) High Blood Pressure and Diet Quality in the Spanish Childhood Population. J Hypertens 2: 115. doi:10.4172/2167-1095.1000115

Page 3 of 7

experienced a significant increase during the growth period analyzed (Table 2).

As for the quality of the diet (Table 3), the highest proportion of schoolchildren $(63.07 \%)$ was in the "average" category (KIDMED score 4-7), although the percentage of individuals with "good" diet (KIDMED score $\geq 8$ ) was higher in girls $(6.56 \%)$ than in boys (2.52\%). Analyzing separately the items of KIDMED index, differences were observed for consumption of fruit and vegetables in favor of the female series. By contrast, boys had higher consumption of cereals and yoghurts, but the mean KIDMED score was similar in both sexes ( 4.38 for girls and 4.86 for boys). The association between degree of adherence to MD and BP is evident in the results presented in table 4. It is shown that median SBP and DPB significantly increase at the same time that diminished the quality of the diet. In table 5 we observe that schoolchildren with HBP (4.66\% boys; $4.78 \%$ girls) are not distributed uniformly in the different KIDMED categories. There were not hypertensive children in "good" categories and, by contrast, the HBP proportion in the "poor" diet groups $(8.33 \%)$ was more than double than the proportion observed in the "average" categories (3.38\%). Another way to demonstrate this association is the performed multiple linear regression (Table 6). It was found that KIDMED index had a negative correlation with SBP and DBP. Also BMI and WtHR were determinants of both BP levels (positive correlations) and \%BF was positive associated with DBP.

\section{Discussion}

In this paper, the association of diet quality and BP in healthy Spanish schoolchildren was analyzed. The major findings were that children with low level of adherence to MD had a significantly higher SBP and DBP levels compared to their peers with high KIDMED score.

The level of adherence to the MD, in our sample resulted lower than other Spanish populations such as Granadian schoolchildren studied in 2008 by Mariscal-Arcas et al., and that in the Madrilenian boys and girls analyzed by Montero in 2006 [34-36]. In these samples, the percentage of subjects classified with "good" diet was $48.6 \%$ and $37.5 \%$ respectively, although the latter were among a nutrition education program at school. Our data are closer to those obtained for the Balearic Islands, where the average degree of adhesion to MD among adolescents of 12 to 17 years was $57.9 \%$ [37].

The prevalence of excess weight (30.5\%) was similar to that obtained

\begin{tabular}{|c|c|c|c|c|c|c|c|c|c|c|c|c|c|c|c|}
\hline \multicolumn{16}{|c|}{ Males } \\
\hline \multirow[t]{2}{*}{ Age } & \multirow[t]{2}{*}{$\mathbf{N}$} & \multicolumn{2}{|c|}{ Height (cm) } & \multicolumn{2}{|c|}{ Weight (kg) } & \multicolumn{2}{|c|}{ BMI $\left(\mathbf{k g} / \mathbf{m}^{2}\right)$} & \multicolumn{2}{|c|}{$\sum 4$ skinfolds $(\mathrm{mm})$} & \multicolumn{2}{|c|}{$\% \mathrm{BF}$} & \multicolumn{2}{|c|}{ WC (cm) } & \multicolumn{2}{|c|}{ WtHR } \\
\hline & & Mean & SD & Mean & SD & Mean & SD & Mean & SD & Mean & SD & Mean & SD & Mean & SD \\
\hline 9 & 33 & 137.58 & 5.89 & 34.24 & 7.62 & 17.99 & 3.19 & 42.17 & 21.75 & 23.67 & 7.81 & 65.54 & 8.56 & 0.455 & 0.05 \\
\hline 10 & 36 & 143.15 & 6.46 & 41.00 & 9.88 & 19.82 & 3.64 & 51.31 & 25.46 & 26.82 & 7.83 & 70.74 & 10.34 & 0.463 & 0.06 \\
\hline 11 & 43 & 147.71 & 7.32 & 44.66 & 10.01 & 20.17 & 3.19 & 52.19 & 24.55 & 25.32 & 8.52 & 71.35 & 8.82 & 0.459 & 0.04 \\
\hline 12 & 90 & 151.60 & 7.47 & 47.84 & 11.07 & 20.47 & 3.56 & 48.04 & 25.80 & 20.52 & 6.95 & 70.92 & 9.80 & 0.460 & 0.05 \\
\hline 13 & 77 & 159.68 & 7.68 & 52.90 & 10.60 & 20.69 & 3.59 & 48.34 & 21.23 & 20.22 & 6.77 & 72.47 & 8.83 & 0.440 & 0.04 \\
\hline 14 & 129 & 165.99 & 7.85 & 56.89 & 9.73 & 20.60 & 3.07 & 49.25 & 17.31 & 17.36 & 5.97 & 72.91 & 7.00 & 0.454 & 0.05 \\
\hline 15 & 64 & 170.30 & 7.37 & 61.01 & 11.04 & 20.99 & 3.45 & 50.31 & 16.78 & 17.75 & 5.61 & 73.84 & 7.15 & 0.450 & 0.03 \\
\hline 16 & 42 & 172.63 & 6.11 & 68.50 & 8.71 & 22.31 & 2.76 & 49.97 & 19.27 & 18.28 & 5.29 & 74.25 & 8.54 & 0.482 & 0.04 \\
\hline \multicolumn{16}{|c|}{ Females } \\
\hline \multirow[b]{2}{*}{ Age } & \multirow[b]{2}{*}{$\mathbf{N}$} & \multicolumn{2}{|c|}{ Height (cm) } & \multicolumn{2}{|c|}{ Weight (kg) } & \multicolumn{2}{|c|}{ BMI $\left(\mathbf{k g} / \mathbf{m}^{2}\right)$} & \multicolumn{2}{|c|}{$\sum 4$ skinfolds $(\mathrm{mm})$} & \multicolumn{2}{|c|}{$\% \mathrm{BF}$} & \multicolumn{2}{|c|}{ WC (cm) } & \multicolumn{2}{|c|}{ WtHR } \\
\hline & & Mean & SD & Mean & SD & Mean & $\mathrm{SD}$ & Mean & SD & Mean & SD & Mean & SD & Mean & $\mathrm{SD}$ \\
\hline 9 & 44 & 136.75 & 7.21 & 34.55 & 8.38 & 18.28 & 3.20 & 47.09 & 19.00 & 25.34 & 5.29 & 64.52 & 8.49 & 0.450 & 0.05 \\
\hline 10 & 47 & 142.03 & 7.50 & 38.22 & 7.95 & 18.82 & 3.04 & 45.11 & 19.04 & 24.41 & 5.12 & 65.87 & 8.48 & 0.451 & 0.05 \\
\hline 11 & 64 & 148.18 & 7.65 & 43.74 & 9.77 & 19.78 & 3.47 & 46.06 & 21.40 & 25.16 & 5.64 & 67.17 & 8.20 & 0.457 & 0.05 \\
\hline 12 & 114 & 153.94 & 6.47 & 48.56 & 9.44 & 20.44 & 3.54 & 50.52 & 20.98 & 26.47 & 5.41 & 68.08 & 7.12 & 0.445 & 0.05 \\
\hline 13 & 83 & 158.01 & 6.38 & 52.98 & 9.79 & 21.23 & 3.74 & 53.22 & 21.60 & 26.83 & 4.80 & 69.99 & 6.97 & 0.447 & 0.05 \\
\hline 14 & 119 & 158.99 & 6.28 & 54.40 & 10.67 & 21.05 & 3.68 & 53.34 & 21.00 & 27.74 & 3.94 & 68.94 & 5.96 & 0.432 & 0.04 \\
\hline 15 & 45 & 160.56 & 6.47 & 55.24 & 8.45 & 21.43 & 2.94 & 54.10 & 27.20 & 28.24 & 4.21 & 68.99 & 6.12 & 0.438 & 0.04 \\
\hline 16 & 48 & 162.44 & 6.07 & 56.48 & 7.77 & 21.39 & 2.73 & 56.83 & 28.40 & 27.56 & 3.15 & 69.37 & 5.85 & 0.437 & 0.04 \\
\hline
\end{tabular}

BMI: Body Mass Index; $\sum 4$ skinfolds (biceps+triceps+subscapular+suprailiac); \%BF: percent Body Fat by Siri equation; WC: waist circumference; WtHR: Waist to Height Ratio

Table 1: Descriptive anthropomeric characteristics of sample.

\begin{tabular}{|c|c|c|c|c|c|c|c|c|c|c|}
\hline \multirow{3}{*}{ Age } & \multicolumn{5}{|c|}{ Males } & \multicolumn{5}{|c|}{ Females } \\
\hline & \multirow[t]{2}{*}{$\mathbf{N}$} & \multicolumn{2}{|c|}{ SBP } & \multicolumn{2}{|c|}{ DBP } & \multirow[t]{2}{*}{$\mathbf{N}$} & \multicolumn{2}{|c|}{ SBP } & \multicolumn{2}{|c|}{ DBP } \\
\hline & & Mean & SD & Mean & SD & & Mean & SD & Mean & SD \\
\hline 9 & 33 & 102.60 & 11.7 & 61.37 & 0.93 & 44 & 100.42 & 1.16 & 59.59 & 0.67 \\
\hline 10 & 36 & 104.48 & 11.9 & 62.19 & 0.86 & 47 & 103.66 & 1.22 & 60.89 & 0.81 \\
\hline 11 & 43 & 104.97 & 15.5 & 64.04 & 1.18 & 64 & 105.95 & 1.31 & 62.54 & 0.79 \\
\hline 12 & 90 & 104.67 & 12.5 & 61.23 & 0.93 & 114 & 104.30 & 1.04 & 63.71 & 0.89 \\
\hline 13 & 77 & 109.87 & 12.8 & 62.10 & 1.06 & 83 & 110.31 & 1.11 & 64.66 & 0.86 \\
\hline 14 & 129 & 112.01 & 10.3 & 64.56 & 0.86 & 119 & 108.56 & 1.07 & 61.89 & 0.80 \\
\hline 15 & 64 & 113.15 & 10.3 & 65.26 & 0.93 & 45 & 110.71 & 0.90 & 63.37 & 0.79 \\
\hline 16 & 42 & 119.21 & 10.5 & 70.60 & 1.04 & 48 & 114.18 & 1.13 & 74.00 & 0.91 \\
\hline ANOVA & & $F=9.39$ & $p<0.001$ & $F=6.26$ & $p<0.001$ & & $F=6.09$ & $p<0.001$ & $F=13.63$ & $p<0.001$ \\
\hline
\end{tabular}


Citation: Marrodán MD, López-Ejeda N, González-Montero de Espinosa M, Martínez-Álvarez JR, et al. (2013) High Blood Pressure and Diet Quality in the Spanish Childhood Population. J Hypertens 2: 115. doi:10.4172/2167-1095.1000115

Page 4 of 7

\begin{tabular}{|c|c|c|c|c|}
\hline KIDMED items & Males (\%) & Females (\%) & Total (\%) & $p$ value \\
\hline Fruit or fruit juice daily & 55.3 & 70.1 & 63.8 & ** \\
\hline Second serving of fruit daily & 22.8 & 29.4 & 26.6 & NS \\
\hline Fresh or cooked vegetables daily & 50.0 & 50.0 & 50.0 & NS \\
\hline Fresh or cooked vegetables $>1 /$ day & 21.5 & 29.9 & 26.3 & ** \\
\hline Regular fish consumption (at least 2-3/week) & 57.0 & 59.0 & 58.9 & NS \\
\hline Fast-food >1/week & 32.2 & 29.3 & 31.0 & NS \\
\hline Pulses >1/week & 49.7 & 45.1 & 47.0 & NS \\
\hline Pasta or rice almost ( $\geq 5$ /week) & 30.9 & 24.0 & 26.9 & NS \\
\hline Cereal productforbreakfast & 38.7 & 27.0 & 31.9 & * \\
\hline Regular nut consumption (at least 2-3/week) & 4.0 & 4.4 & 4.2 & NS \\
\hline Use of olive oil at home & 100 & 100 & 100 & NS \\
\hline No breakfast & 4.7 & 7.3 & 6.2 & NS \\
\hline Dairy products for breakfast & 88.0 & 88.3 & 88.2 & NS \\
\hline Commercially baked goods or pastries for breakfast & 6.0 & 5.4 & 5.7 & NS \\
\hline Two yoghurts and/or $40 \mathrm{~g}$ cheese daily & 4.7 & 1.5 & 2.8 & * \\
\hline Sweets and candy several times a day & 10.1 & 9.3 & 9.6 & NS \\
\hline \multicolumn{5}{|l|}{ KIDMED categories } \\
\hline Poor ( $\leq 3$ score $)$ & 35.99 & 28.90 & 32.28 & \multirow[t]{3}{*}{ * } \\
\hline Average (4-7 score) & 61.47 & 64.53 & 63.07 & \\
\hline Good( $\geq 8$ score) & 2.52 & 6.56 & 4.63 & \\
\hline Mean KIDMED-score (SD) & $4.38(1.85)$ & $4.86(1.77)$ & $4.37(1.82)$ & NS \\
\hline
\end{tabular}

Table 3: KIDMED-index scores. ${ }^{*} p<0.05 ;{ }^{* *} p<0.001$, NS: no significant differences $\left(X^{2}\right.$ test $)$

\begin{tabular}{|c|c|c|c|c|c|c|c|c|}
\hline \multirow{3}{*}{ KIDMED index scores } & \multicolumn{4}{|c|}{ Males } & \multicolumn{4}{|c|}{ Females } \\
\hline & \multicolumn{2}{|c|}{ SBP } & \multicolumn{2}{|c|}{ DBP } & \multicolumn{2}{|c|}{ SBP } & \multicolumn{2}{|c|}{ DBP } \\
\hline & Mean & SD & Mean & SD & Mean & SD & Mean & SD \\
\hline Poor $(\leq 3)$ & 117.25 & 12.06 & 66.53 & 8.78 & 111.03 & 11.71 & 64.55 & 9.28 \\
\hline Average (4-7) & 112.96 & 11.02 & 64.34 & 8.88 & 107.68 & 9.78 & 61.76 & 7.13 \\
\hline Good $(\geq 8)$ & 106.68 & 10.15 & 64.05 & 7.54 & 107.02 & 10.17 & 62.97 & 4.59 \\
\hline ANOVA & \multicolumn{2}{|l|}{$F=21.04$} & \multicolumn{2}{|l|}{$F=10.94$} & \multicolumn{2}{|r|}{$p<0.001$} & \multicolumn{2}{|c|}{$F=11.20$} \\
\hline
\end{tabular}

Table 4: Mean sistolic (SBP) and diastolic (DBP) blood pressure by KIDMED categories.

\begin{tabular}{|c|c|c|c|}
\hline $\begin{array}{l}\text { KIDMED } \\
\text { categories }\end{array}$ & $\begin{array}{l}\text { Males } \\
\mathrm{N}(\%)\end{array}$ & $\begin{array}{c}\text { Females } \\
\mathrm{N}(\%)\end{array}$ & $\begin{array}{l}\text { Total } \\
\mathrm{N}(\%)\end{array}$ \\
\hline Poor ( $\leq 3$ score) & $14(7.50)$ & $15(9.20)$ & $29(8.33)$ \\
\hline Average (4-7 score) & $11(3.48)$ & $12(3.29)$ & $23(3.38)$ \\
\hline Good ( $\geq 8$ score) & -- & -- & -- \\
\hline Total & $24(4.66)$ & $27(4.78)$ & $52(4.82)$ \\
\hline
\end{tabular}

Table 5: Children with high blood pressure (HBP) by KIDMED categories.

\begin{tabular}{|c|c|c|c|c|c|c|c|c|c|c|c|}
\hline & \multirow[b]{2}{*}{ Ajusted $\mathbf{R}^{2}$} & \multicolumn{2}{|c|}{ BMI } & \multicolumn{2}{|c|}{$\%$ BF } & \multicolumn{2}{|c|}{ WtHR } & \multicolumn{2}{|c|}{ KIDMED index } & \multicolumn{2}{|c|}{ Sex } \\
\hline & & Beta & pvalue & Beta & $p$ value & Beta & pvalue & Beta & pvalue & Beta & pvalue \\
\hline SBP & 0.492 & 0.443 & 0.001 & 0.237 & 0.001 & 0.240 & 0.001 & -0.261 & 0.001 & -0.116 & 0.001 \\
\hline DBP & 0.369 & 0.269 & 0.001 & 0.106 & 0.001 & 0.121 & 0.041 & -0.162 & 0.012 & -0.011 & 0.716 \\
\hline
\end{tabular}

BMI: Body Mass Index; \%BF: percent Body Fat by Siri equation; WtHR: Waist to Height Ratio

Table 6: Multiple linear regression analysis. Dependent variables: Sistolic blood pressure (SBP); Diastolic blood pressure (DBP) Sex code: 1 male. 2 female.

in the ALADINO Study (Actividad Física, Obesidad y Desarrollo Infantil [Food Physical Activity Obesity and Child Development]) conducted in 2010 in which was reported a $31.3 \%$ (overweight plus obesity) on a sample of 7923 Spanish schoolchildren between 6 and 9.99 years [38]. Also, our data coincide with those obtained in the enKID study conducted in the past decade (30.4\%) and are very close to those reported for other Mediterranean countries as Portugal (31.5\%) and Italy $(25.1 \%-27.6 \%)$ [39-41]. On the other hand, are lower than the values obtained in Greece (overweight: $30.3 \%$ and obese: $13.0 \%$ ) and higher than those corresponding to Morocco and Tunisia where overweight children are below $10.0 \%$ [22,42-44].

In Spain, the nutritional transition has been characterized by an increase of total energy consumption and a gradual abandonment of the MD. Since the 60s of last century, the proportion of protein and animal fat and sugary products with low nutrient density (sweets, candy, soft drinks, etc.) has augmented. At the same time the consumption of bread, cereals and legumes has decreased [45]. This phenomenon, together with the increasing of sedentarism and the decreasing of sleeping hours, has led to the rise of obesity both in adults and in children and adolescents [46].

In parallel to the increase in childhood obesity has detected an augmentation in BP at an early age. Several studies have discussed this aspect, revealing a significant association between excess adiposity and risk of hypertension in children. Years ago, classic studies like 
the Bogalusa Heart Study or the Muscatine Study found a positive correlation between body weight, BMI, and BP. More recent studies have focused on the importance of $\% \mathrm{BF}$ and fat distribution as determinates of arterial pressure levels [44,47-51]. In this line, our research group found that the risk of HBP in children was increased with a body mass index indicative of obesity (7.87-fold in boys, 12.32 fold in girls), with a $\% \mathrm{BF}>97^{\text {th }}$ percentile (6.98-fold in boys, 18.51 -fold in girls), or with a WtHR $\geq 0.5$ (10.56-fold in boys, 7.82 -fold in girls) [52].

The works relating diet and $\mathrm{BP}$ or other indicators of cardiometabolic risk in children are still scarce. Rodriguez-Aralejo et al. in a study with 1112 kids aged 6-7 years, found a strong relationship between dietary patterns and different cardiovascular mortality in four Spanish cities with varying degrees of adherence to traditional MD [53]. In cities with high mortality by ischemic heart diseases (Cadiz, Murcia), the children consumed more precooked foods and soft drinks (products with high content in salt and refined sugars), but also more cheese and yogurt. In cities with lower mortality, children ate more fruit and milk. In children from the four cities, no differences were found for the prevalence of overweight (considered as BMI >17.6) and obesity (BMI >20.1) with values that ranged from $28.9 \%$ to $34.5 \%$ and $8.5 \%$ to $15.7 \%$ respectively. It therefore appears that nutritional factors in early stages of life may contribute to cardiovascular disease in adults although diet had no apparent effect on the excess of weight.

On the same line, Lydakis et al. in a sample of 277 Greek children aged 12 years, observed that the KIDMED score is negatively associated to "augmentation index" in the brachial artery, regardless of BMI [22]. This study was the first to analyze the relationship between MD and arterial stiffness in children, although a previous study had proven that daily consumption of fruits and vegetables (included as items in the KIDMED index) during childhood, was a protective factor for hypertension and arterial stiffness in adults [54]. Similarly, in a sample of children from the Framingham prospective study, the researchers found that boys and girls who consumed four or more servings, either of fruit or vegetables, per day had smaller yearly gains in SPB throughout their growth period [55].

In the Cyprus Kids Study (CYKIDS) made by Lazarou et al. on a sample of 622 Cypriot schoolchildren, were explored the relationship between diet quality (assessed by the "Electronic Kids Dietary Index" or E-KINDEX) and BP [56]. Researchers confirmed that E-KINDEX score was inversely correlated with SBP and DBP levels once adjusted for gender, age, obesity, parental status and parental educational level; particularly children who scored below the mean were 2.3 times more likely to have HBP. The E-KINDEX questionnaire includes 13 components that assess consumption frequency of foods or 11 major groups of foods, as well as two cooking techniques (frying and grilling). This index is relatively similar to KIDMED index, and the frequent consumption of fruit, vegetables, legumes, fish and milk contributes to obtain higher scores. Clearly, these products, key elements of the MD, are rich in potassium, calcium, vitamins, antioxidants and Omega-3 fatty acids, which have a protective role against $\operatorname{HBP}[57,58]$.

The results discussed and those obtained in this article for child population are consistent with those observed in Spanish adults and replicate the findings described in the ATTICA study with Greek adult population in which is noted that higher adherence to the MD is a protective factor against the development of hypertension $[59,60]$. This protection seems to act even when there are alleles of genetic predisposition to this disease as demonstrated by Godoy et al. for the $\mathrm{G}$ allele (rs3101336) in the NEGR1 gene [61].
It should be added that some research shows high prevalences of childhood hypertension, even though the food habits were correct and they were included in the MD. This is the case observed in Roman schoolchildren with $7.8 \%$ of hypertension that researchers justified by excess of salt added to the food [62]. In this regard, GRECO (Greek Childhood Obesity) Study also revealed that there was a high salt intake in children classified as "average" or "good" diet by KIDMED index [63]. It must keep in mind that the contents of salt in bread or cheese, both foods positively evaluated in this questionnaire, may be elevated.

\section{Limitations}

To provide greater consistency to present work, it would be interesting to consider other aspects that may eventually affect $\mathrm{BP}$ values in children such as birth weight, breastfeeding patterns or sleep habits. Furthermore, although take three successive measurements of BP would be appropriate to perform a longitudinal study of the participants. This would ensure that the hypertensive state is a real and permanent status in children affected and not the result of the specific situation in which the measurement was taken.

Regarding the assessment of the diet quality, anytype of questionnaire involves some subjectivity and depends on the memory capacity of the individual who is being interviewed. However a food frequency questionnaire as the KIDMED index involves fewer inaccuracies than those obtained by the $24 \mathrm{~h}$ recall surveys, the other technique most usually employed in this kind of studies. In addition the separate study of the items can make this index be much more informative and also, it would better explain the results of the epidemiological studies which link diet quality with any child component of the metabolic syndrome like hypertension, hypercholesterolemia, hypertriglyceridemia, and diabetes.

\section{Conclusion}

There is an inverse association between diet quality and BP in healthy Spanish schoolchildren: children with low level of adherence to MD had had a significantly higher in SBP and DBP levels compared to their peers with high KIDMED score.

\section{Sources of Support}

The study was financed by the Ministry of Education and Science of the Government of Spain (CGL-2005/03752) and supported by the Education Department of the Community of Madrid.

\section{References}

1. Pereira M, Lunet N, Azevedo A, Barros $H$ (2009) Differences in prevalence, awareness, treatment and control of hypertension between developing and developed countries. J Hypertens 27: 963-975

2. World Health Organization (WHO) (2013) A global brief on hypertension. Silent killer, global public health crisis. Geneva: WHO Press.

3. Kavey RE, Daniels SR, Flynn JT (2010) Management of high blood pressure in children and adolescents. CardiolClin 28: 597-607.

4. Salvadori M, Sontrop JM, Garg AX, Truong J, Suri RS, et al. (2008) Elevated blood pressure in relation to overweight and obesity among children in a rura Canadian community. Pediatrics 122: e821-827.

5. Bojórquez Cl, Angulo CM, Reynoso L (2011) Factores de riesgo de hipertensión arterial en niños de primaria. Psicología y Salud 21: 245-252.

6. Pang W, Sun Z, Zheng L, Li J, Zhang X, et al. (2008) Body mass index and the prevalence of prehypertension and hypertension in a Chinese rural population. Intern Med 47: 893-897.

7. Raj M, Krishnakumar R (2013) Hypertension in children and adolescents: epidemiology and pathogenesis. Indian J Pediatr 80 Suppl 1: S71-76. 
Citation: Marrodán MD, López-Ejeda N, González-Montero de Espinosa M, Martínez-Álvarez JR, et al. (2013) High Blood Pressure and Diet Quality in the Spanish Childhood Population. J Hypertens 2: 115. doi:10.4172/2167-1095.1000115

Page 6 of 7

8. McNiece KL, Poffenbarger TS, Turner JL, Franco KD, Sorof JM, et al. (2007) Prevalence of hypertension and pre-hypertension among adolescents. J Pediatr 150: 640-644, 644

9. Falkner B (2010) Hypertension in children and adolescents: epidemiology and natural history. PediatrNephrol 25: 1219-1224.

10. Sacks FM, Svetkey LP, Vollmer WM, Appel LJ, Bray GA, et al. (2001) Effects on blood pressure of reduced dietary sodium and the Dietary Approaches to Stop Hypertension (DASH) diet. DASH-Sodium Collaborative Research Group. N Engl J Med 344: 3-10.

11. Williams CL, Hayman LL, Daniels SR, Robinson TN, Steinberger J, et al. (2002) Cardiovascular health in childhood: A statement for health professionals from the Committee on Atherosclerosis, Hypertension, and Obesity in the Young (AHOY) of the Council on Cardiovascular Disease in the Young, American Heart Association. Circulation 106: 143-160.

12. Couch SC, Saelens BE, Levin L, Dart K, Falciglia G, et al. (2008) The efficacy of a clinic-based behavioral nutrition intervention emphasizing a DASH-type diet for adolescents with elevated blood pressure. J Pediatr 152: 494-501.

13. Bonaccio M, Bonanni AE, Di Castelnuovo A, De Lucia F, Donati MB, et al. (2012) Low income is associated with poor adherence to a Mediterranean die and a higher prevalence of obesity: cross-sectional results from the Moli-san study. BMJ Open 2.

14. Serra-Majem L, Ribas L, García A, Pérez-Rodrigo C, Aranceta J (2003) Nutrient adequacy and Mediterranean Diet in Spanish school children and adolescents. Eur J ClinNutr 57 Suppl 1: S35-39.

15. Tur JA, Romaguera D, Pons A (2004) Adherence to the Mediterranean dietary pattern among the population of the Balearic Islands. Br J Nutr 92: 341-346.

16. Mariscal-Arcas M, Romaguera D, Rivas A, Feriche B, Pons A, et al. (2007) Diet quality of young people in southern Spain evaluated by a Mediterranean adaptation of the Diet Quality Index-International (DQI-I). Br J Nutr 98: 12671273.

17. Bach-Faig A, Fuentes-Bol C, Ramos D, Carrasco JL, Roman B, et al. (2011) The Mediterranean diet in Spain: adherence trends during the past two decades using the Mediterranean Adequacy Index. Public Health Nutr 14: 622-628.

18. Delgado FJ, Pérez-Herrera A, Pérez-Caballero Al, Pérez-Jiménez F (2009) Dietamediterránea y prevención cardiovascular. Rev EspObes 7: 135-143.

19. Estruch R, Ros E, Salas-Salvadó J, Covas MI, Corella D, et al. (2013) Primary prevention of cardiovascular disease with a Mediterranean diet. N Engl J Med 368: $1279-1290$

20. Strazzullo P, Ferro-Luzzi A, Siani A, Scaccini C, Sette S, et al. (1986) Changing the Mediterranean diet: effects on blood pressure. J Hypertens 4: 407-412.

21. Estruch R, Martínez-González MA, Corella D, Salas-Salvadó J, Ruiz-Gutiérrez $\mathrm{V}$, et al. (2006) Effects of a Mediterranean-style diet on cardiovascular risk factors: a randomized trial. Ann Intern Med 145: 1-11.

22. Lydakis C, Stefanaki E, Stefanaki S, Thalassinos E, Kavousanaki M, et al. (2012) Correlation of blood pressure, obesity, and adherence to the Mediterranean diet with indices of arterial stiffness in children. Eur J Pediatr 171: 1373-1382.

23. World Medical Association (WMA) (2000) Helsinki Declaration: Ethical principles for medical research involving human subjects. Helsinki.

24. Weiner JS, Lourie JA (1981) Practical Human Biology. London: Academic Press.

25. Cabañas MD, Esparza F (2009) Compendio de Cineantropometría. Madrid: Grupo CTO.

26. Siri WE (1961) Body composition from fluid spaces and density. In: Brozeck $\mathrm{J}$, Henschel A (editors). Techniques for measuring body composition. Washington: National Academy of Sciences.

27. Brook CG (1971) Determination of body composition of children from skinfold measurements. Arch Dis Child 46: 182-184.

28. Durnin JV, Rahaman MM (1967) The assessment of the amount of fat in the human body from measurements of skinfold thickness. Br J Nut 21: 681-689.

29. Cole TJ, Bellizzi MC, Flegal KM, Dietz WH (2000) Establishing a standard definition for child overweight and obesity worldwide: international survey. BMJ 320: $1240-1243$

30. Cole TJ, Flegal KM, Nicholls D, Jackson AA (2007) Body mass index cut offs to define thinness in children and adolescents: international survey. BMJ 335 194

31. Spanish Cooperative Group for the Study of Cardiovascular Risk Factors in Childhood and Adolescence. (1995) Factores de riesgo cardiovascular en la infancia y la adolescencia en España. Estudio RICARDIN II: valores de referencia. An EspPediatr 43: 11-17.

32. National High Blood Pressure Education Program Working Group on High Blood Pressure in Children and Adolescents (2004) The fourth report on the diagnosis, evaluation, and treatment of high blood pressure in children and adolescents. Pediatrics 114: 555-576.

33. Cook S, Weitzman M, Auinger P, Nguyen M, Dietz WH (2003) Prevalence of a metabolic syndrome phenotype in adolescents: findings from the third National Health and Nutrition Examination Survey, 1988-1994. Arch PediatrAdolesc Med 157: 821-827

34. Serra-Majem L, Ribas L, Ngo J, Ortega RM, García A, et al. (2004) Food, youth and the Mediterranean diet in Spain. Development of KIDMED, Mediterranean Diet Quality Index in children and adolescents. Public Health Nutr 7: 931-935.

35. Mariscal-Arcas M, Rivas A, Velasco J, Ortega M, Cballero AM, et al. (2005) Evaluation of the Mediterranean Diet Quality index (KIDMED) in children and adolescents in Southern Spain. Public Health Nutr 12: 1408-1412.

36. Montero P (2006) Indicateurs de qualité de l'alimentation chez les enfants: l'indice KIDMED. Antropo 11: 189-197.

37. Martínez E, Llull R, Del Mar Bibiloni M, Pons A, Tur JA (2011) Adherence to the Mediterranean dietary pattern among Balearic Islands adolescents. J Hypertens 29: 1069-1076.

38. Agency for food safety and nutrition (Agencia de seguridadalimentaria y nutrición, AESAN) (2011). Estudio de prevalencia de la obesidadinfantil, Estudio ALADINO. Madrid: Ministerio de Sanidad, Política Social e Igualdad.

39. Serra-Majem L, García-Closas R, Ribas L, Pérez-Rodrigo C, Aranceta J (2001) Food patterns of Spanish schoolchildren and adolescents: The enKid Study. Public Health Nutr 4: 1433-1438.

40. Padez C, Fernandes T, Mourão I, Moreira P, Rosado V (2004) Prevalence of overweight and obesity in 7-9-year-old Portuguese children: trends in body mass index from 1970-2002. Am J Hum Biol 16: 670-678.

41. Celi F, Bini V, De Giorgi G, Molinari D, Faraoni F, et al. (2003) Epidemiology of overweight and obesity among school children and adolescents in three provinces of central Italy, 1993-2001: study of potential influencing variables. Eur J Clin Nutr 57: 1045-1051.

42. Hassan B, Rguibi M (2012) Nutritional paradox of the Moroccan population coexistence of undernutrition and obesity. Nutr Clin Diet Hosp 32: S70-S75.

43. Mora Al, Montero $\mathrm{P}$, Marrodán MD, Romero-Collazos JF, Carmenate MM, et al. (2012) Efecto de la transiciónnutricionalsobre el crecimiento y desarrollo de adolescentesmarroquíes. In: Turbón D, Fañanás L, Rissech C, Rosa A (editors) Biodiversidadhumana y evolución. Barcelona: Universitat de Barcelona.

44. Aounallah-Skhiri H, El Ati J, Traissac $\mathrm{P}$, Ben Romdhane H, Eymard-Duvernay $S$, et al. (2012) Blood pressure and associated factors in a North African adolescent population. a national cross-sectional study in Tunisia. BMC Public Health 12: 98

45. Marrodán MD, Montero $P$, Cherkaoui $M$ (2012) Transición nutricional en España durante la historia reciente. Nutr Clin Diet Hosp 32: S55-S64.

46. González Montero de Espinosa M, Herráez A, Marrodán Serrano MD (2013) Determining factors in body mass index of Spanish schoolchildren based on the National Health Surveys. EndocrinolNutr.

47. Voors AW, Foster TA, Frerichs RR, Webber LS, Berenson GS (1976) Studie of blood pressures in children, ages 5-14 years, in a total biracial community: the Bogalusa Heart Study. Circulation 54: 319-327.

48. Lauer RM, Clarke WR, Beaglehole R (1984) Level, trend, and variability of blood pressure during childhood: the Muscatine study. Circulation 69: 242-249.

49. Blanco-Cedres L, Macias-Tomei C, López-Blanco M (2000) Relation among early maturation, body mass index and the longitudinal behavior of systolic blood pressure] ActaCientVenez 51: 252-256.

50. Szer G, Kovalskysa I, De Gregorio MJ (2010) Prevalence of overweight and obesity, and their relation to high blood pressure and central adiposity in students. Arch Argent Pediatr 108: 492-498. 
Citation: Marrodán MD, López-Ejeda N, González-Montero de Espinosa M, Martínez-Álvarez JR, et al. (2013) High Blood Pressure and Diet Quality in the Spanish Childhood Population. J Hypertens 2: 115. doi:10.4172/2167-1095.1000115

Page 7 of 7

51. Pérez-Guillén A, Hernández de Valera Y (2004) Relación de la presión arterial con indicadoresantropométricos de masa y grasa corporal en niños. Antropo 8: 83-92.

52. Marrodán Serrano MD, Cabañas Armesilla MD, Carmenate Moreno MM González-Montero de Espinosa M, López-Ejeda N, et al. (2013) Association Between Adiposity and Blood Pressure Levels Between the Ages of 6 and 16 Years. Analysis in a Student Population From Madrid, Spain. Rev EspCardiol 66: 110-115.

53. Rodríguez-Artalejo F, Garcés C, Gorgojo L, LópezGarcía E, Martín-Moreno JM, et al. (2002) Dietary patterns among children aged 6-7 y in four Spanish cities with widely differing cardiovascular mortality. Eur J ClinNutr 56: 141-148.

54. Aatola H, Koivistoinen T, Hutri-Kähönen N, Juonala M, Mikkilä V, et al. (2010) Lifetime fruit and vegetable consumption and arterial pulse wave velocity in adulthood: the Cardiovascular Risk in Young Finns Study. Circulation 122: 2521-2528.

55. Moore LL, Singer MR, Bradlee ML, Djoussé L, Proctor MH, et al. (2005) Intake of fruits, vegetables, and dairy products in early childhood and subsequent blood pressure change. Epidemiology 16: 4-11.

56. Lazarou C, Panagiotakos DB, Matalas AL (2009) Foods E-KINDEX: a dietary index associated with reduced blood pressure levels among young children: the CYKIDS study. J Am Diet Assoc 109: 1070-1075.
57. Hermansen K (2000) Diet, blood pressure and hypertension. Br J Nutr 83 Suppl 1: S113-119.

58. Srinath Reddy K, Katan MB (2004) Diet, nutrition and the prevention of hypertension and cardiovascular diseases. Public Health Nutr 7: 167-186.

59. León-Muñoz LM, Guallar-Castillón P, Graciani A, López-García E, Mesas AE et al. (2012) Dietary habits of the hypertensive population of Spain: accordance with the DASH diet and the Mediterranean diet. J Hypertens 30: 1373-1382.

60. Panagiotakos DB, Pitsavos CH, Chrysohoou C, Skoumas J, Papadimitriou L, et al. (2003) Status and management of hypertension in Greece: role of the adoption of a Mediterranean diet: the Attica study. J Hypertens 21: 1483-1489.

61. Godoy D, Sorlí JV, Coltell O, Portolés O, Ortega-Azorín C, et al. (2012) 122 modulation by the Mediterranean Diet of the associations between Rapgef 1 and Negr1 polymorphisms and blood pressure in a high cardiovascular risk mediterranean population. J Hypertens 30: e37.

62. Menghetti E, Musacchio P, Tawill L, Vicini S, Spagnolo A (2012) [Obesity and arterial hypertension in children: current calamity]. ClinTer 163: e107-110.

63. Magriplis E, Farajian P, Pounis GD, Risvas G, Panagiotakos DB, et al. (2011) High sodium intake of children through 'hidden' food sources and its association with the Mediterranean diet: the GRECO study. J Hypertens 29: 1069-1076. 